\title{
Acidophilic adenoma of the pituitary with polyneuropathy
}

\author{
U. SANDBANK, B. BORNSTEIN, AND T. NAJENSON \\ From the J. Casper Department of Pathology and the Department of Neurology, \\ Beilinson Medical Center, and the Loewenstein Hospital, Rehabilitation Center, \\ Tel-Aviv University Medical School, Israel
}

SYNOPSIS An acromegalic man aged 70 developed progressive polyneuropathy affecting mainly the extremities. The peripheral nerves showed hypertrophic neuropathy and accumulation of acid mucopolysaccharides in the nerve without 'onion bulb' formation. The myelin showed a lamellar disintegration and vesicular formation. It is suggested that the association of these findings represents a pathological entity, acromegalic polyneuropathy.

Peripheral nerve lesions in acromegalic patients were reported at the beginning of this century. Sainton and State (1900) described various types of peripheral neuralgic pains in acromegalic patients. Absence of tendon reflexes was reported by Oppenheimer (1908) in acromegalic patients and in patients with other hypophyseal tumours: he coined the term 'pseudotabes pituitaria' for the condition. The relation between oversecretion of hypophyseal growth hormone and peripheral nerve lesions was described by Lewis (1972) and Lucey (1972).

The present case, a patient, who suffered from progressive polyneuropathy, had acromegaloid features and an acidophilic adenoma of the hypophysis.

\section{CASE REPORT}

The patient, a man aged 70 years, had always been in good health. His illness started four years previously when he noticed increasing difficulty in walking, instability, and gradual weakness of his legs. He was $1.90 \mathrm{~m}$ tall, with acromegalic features and long hands and feet.

The upper extremities showed bilateral atrophy of the interosseous muscles. The lower extremities showed superficial anaesthesia of a stocking distribution, absence of vibration sense in the same location, ataxia on the knee-heel test, and motor weakness. He was ataxic and walked on a broad base. The Romberg test was positive. The blood glucose concentration and glucose tolerance tests were within normal limits. Radiographs of the skull showed an enlarged sella turcica with porosis of the dorsum sellae. The hands showed osteoporosis of the bones. There were no visual abnormalities and the fundi were normal. An extensive endocrinological study was normal: serum growth hormone level was $2.4 \mathrm{mg} / 100 \mathrm{ml}$., total gonadotropins 22 mouse uterus units $/ 24$ hours, serum protein-bound iodine 4·1-6.3 gamma/100 ml., 17-hydroxycorticosteroids excretion in the urine was $12.8 \mathrm{mg} / 24$ hours, and 17 -ketosteroids $8.7 \mathrm{mg} / 24$ hours. Metopyrone test and blood cortisol variations were normal. Serum vitamin $\mathbf{B}_{12}$ and folic acid were normal.

Pneumoencephalography was normal.

ELECTROPHYSIOLOGICAL STUDIES Concentric needle electrode exploration of muscles was made at various loci. No voluntary action potentials were recorded when the needle was inserted into the flexor hallucis brevis (FHB) and the short extensor muscle of the toes (SET) of both sides. On the left side a few voluntary action potentials were recorded from the long extensor muscle of the toes (LET) and the tibialis anterior (TA) muscle, and a reduced interference pattern was obtained from the quadriceps, abductor pollicis brevis, adductor digiti minimi, and biceps muscles. In none of the examined muscles were any potentials recorded at rest. The duration and amplitude of the motor unit action potentials were within normal values, with a relative increase in polyphasic potentials. No evoked potentials were recorded from the needle in FHB, SET, from stimulation of the tibial nerve and lateral popliteal nerve (LPN), stimulated on both sides with a stimu- 


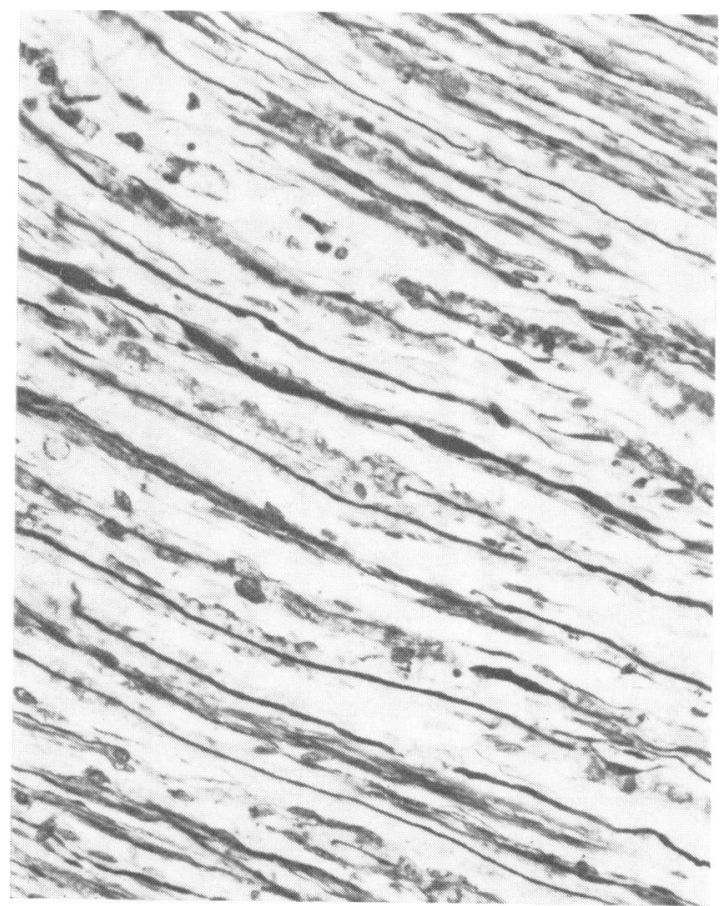

FIG. 1. Glee's silver stain demonstrating diminution of nerve fibres with local thickenings. Glee's silver method, $\times 250$.

lus of $200 \mathrm{~V}$ and $1 \mathrm{~ms}$ duration. Stimulation of the lateral popliteal nerve behind the head of the fibula evoked a response when the needle was inserted in the tibialis anterior muscle and the LET, and was reduced in amplitude and with a latency of $8 \mathrm{~ms}$ for the tibial muscle, and $15 \mathrm{~ms}$ for the LET. Stimulation of the median and ulnar nerves evoked responses in the thenar and hypothenar muscles examined which were reduced in amplitude and nerve conduction velocity between 32 and $35 \mathrm{~ms}$ in both nerves in arm and forearm with a terminal latency of $6 \mathrm{~ms}$ for the ulnar nerve and $9 \mathrm{~ms}$ for the median nerve. The musculocutaneous nerve stimulated in the axilla gave an evoked response in the biceps of near normal amplitude values and latency of $5 \mathrm{~ms}$.

Temporary improvement was achieved with corticosteroid treatment but his condition gradually deteriorated. There was severe atrophy of the legs with disappearance of the reflexes: after a year he was unable to walk. Atrophy of his hands with sensory impairment appeared. He died due to a sudden coma.

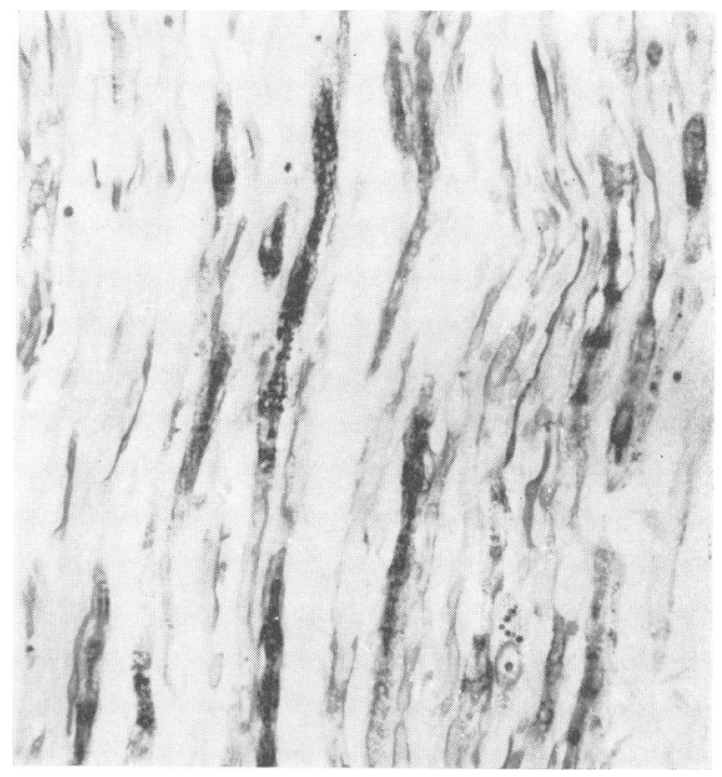

FIG. 2. Nerve with loss of myelin sheaths. Luxol fast blue, $\times 125$.

PATHOLOGICAL FINDINGS All internal organs were heavier and larger than normal. The heart (weight $560 \mathrm{~g}$ ) showed marked hypertrophy of the left ventricle, and there was atherosclerosis of the aorta, coronary, renal, and cerebral arteries. Recent thrombus occluded the right vertebral artery causing recent softening of the right side of the pons. Multiple small softenings were present in the basal ganglia bilaterally.

A few ischaemic foci were dispersed in the white matter of the spinal cord. There was loss of fibres in the posterior column, more pronounced in the gracile tract. The anterior horn cells showed central chromatolysis.

The brachial plexus, sciatic, popliteal, tibial, and sural nerves were thickened, white, and firm. There was severe loss of the larger nerve fibres. Bodian's stain for neurofibrils showed diminution of the nerve fibres with fusiform thickening of the axons (Fig. 1). Luxol fast-blue stain for myelin showed only few myelinated fibres (Fig. 2), the myelin loss being more evident than axonal loss. Longitudinal sections showed typical segmental loss of myelin. The Schwann cells and fibroblasts had proliferated markedly and massive collagen deposits occurred in the epineurium and perineurium (Fig. 3). An excess of collagen fibres and amorphous amphophilic 


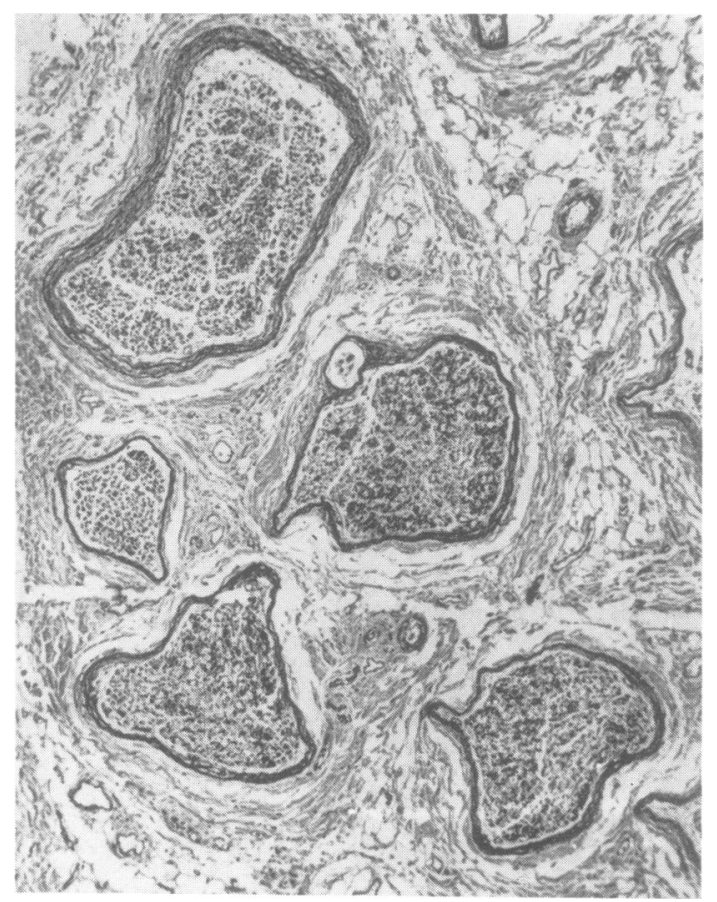

FIG. 3. Abundant collagen fibres in epineurium. Masson trichrome stain, $\times 60$.

material separated the nerve fibres. No 'onion bulb' formations were seen.

Histochemical examination of the amorphous endoneurial material demonstrated that it was moderately PAS-positive, strongly positive with Alcian blue and colloidal iron stains, and was metachromatic with methylene blue (Fig. 4). Sudan II and Sudan black gave negative results. The vasa nervosum appeared normal and no PAS-positive material was detected in the vessel walls.

The psoas, iliac, deltoid, abdominal muscles, and the diaphragm presented a few necrotic muscle fibres without any inflammatory reaction. Some muscle fibres were thin and showed an increased number of central nuclei. Rarely a group of thin muscle fibres were seen and were interpreted as evidence of neurogenic atrophy.

The sella turcica was enlarged and its floor and clinoid processes were destroyed by a multicystic acidophilic adenoma measuring $7 \times 5 \mathrm{~cm}$.

The adrenal glands were small; the cortex was thin and formed of small cells lacking lipids.

Spermatogenesis was absent and no spermatocytes were found in the testes. The Leidig cells showed proliferation.

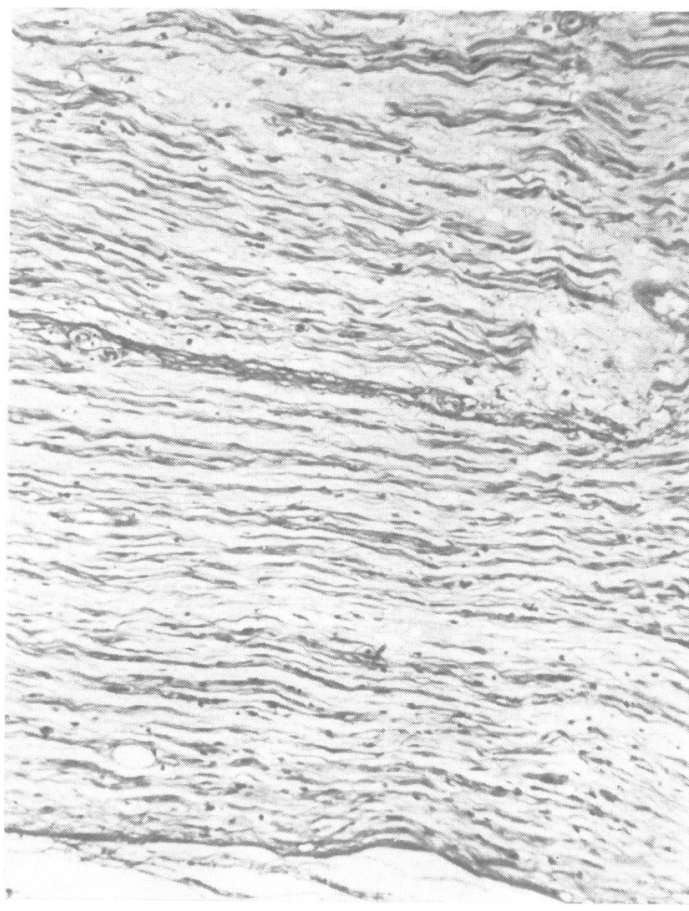

FIG. 4. Accumulation of colloidal iron positiv material between nerve fibres, $\times 250$.

ELECTRONMICROSCOPIC EXAMINATION OF POPLITEAL NERVE Small parts of the nerve fixed in $10 \%$ formalin for six weeks were postfixed in $\mathrm{OsO}_{4}$ and embedded in Epon. Ultrathin sections were stained with lead citrate and uranyl acetate.

Few normal myelinated or unmyelinated nerve fibres were seen. The axons were packed with neurofilaments, vesicles, and membranous debris. Most fibres were thickened and the myelin was split into several layers (Fig. 5) and exhibited a vesicular appearance; the vesicles surrounded by one or two lamellae of myelin lay in regular rows (Fig. 6). Between the myelin layers and around the nerve fibre granular material occurred. The Schwann cell cytoplasm was abundant and contained large amounts of Pi-granules. All other organelles had been destroyed due to postmortem change and inadequate fixation. Abundant collagen fibres surrounded the nerve fibres.

\section{DISCUSSION}

This patient presented a progressive peripheral polyneuropathy in association with acromegaly and acidophilic adenoma of the hypophysis. The electrophysiological findings indicate reduction 


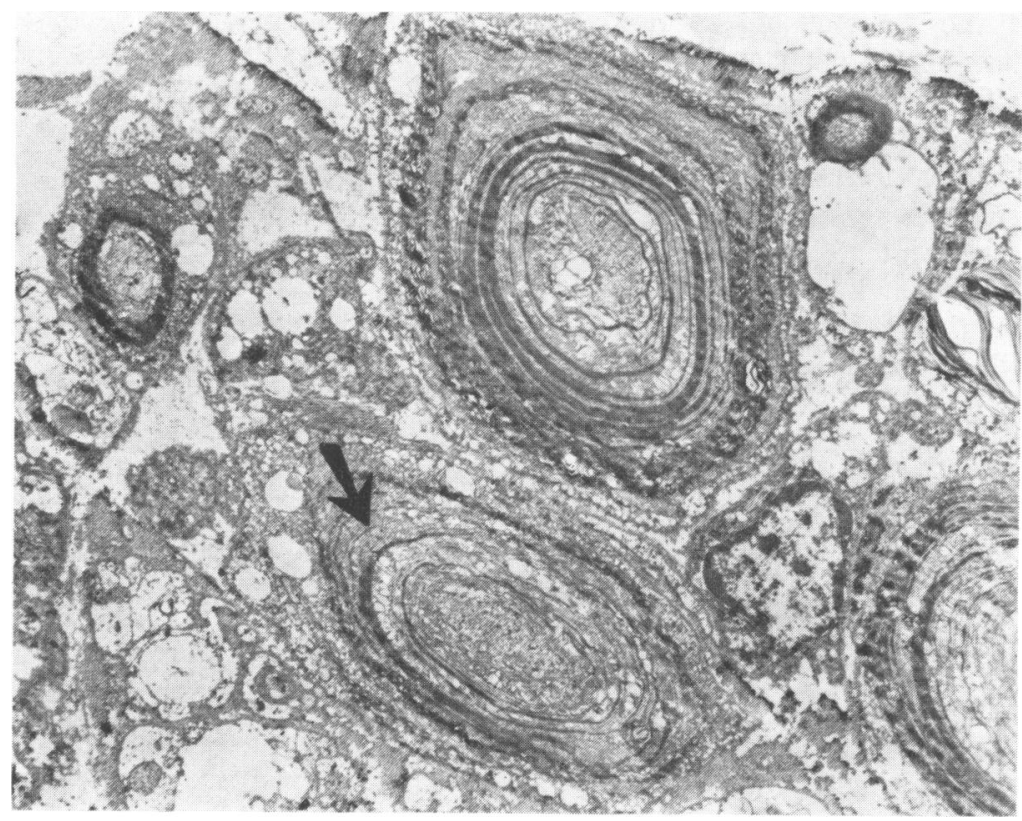

FIG. 5. Thickened nerve fibres with splitting of myelin lamellae and accumulation of granular material around nerve fibres (arrow), $\times 3,400$.

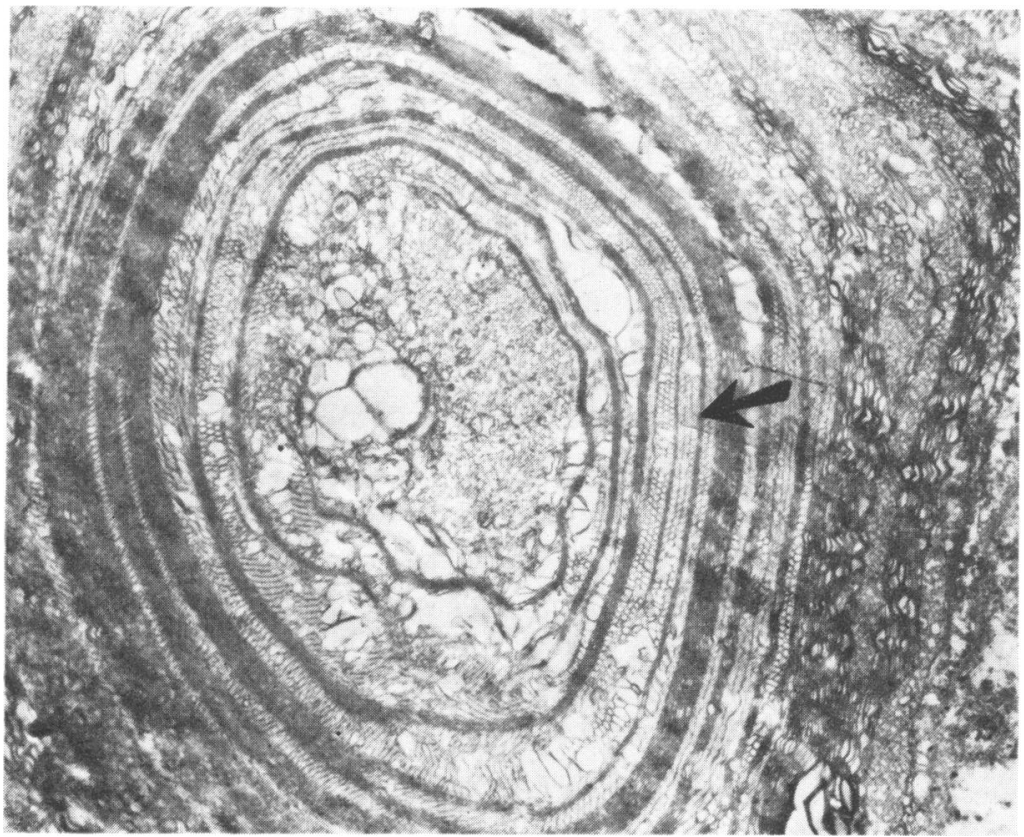

FIG. 6. Splitting of myelin with vesicular formation. Axon shows abundant neurofilaments and vesicles, $\times 18,000$. 
of the conducting fibres in all the nerves examined, being prominent in distal muscles particularly in the lower limbs. No functioning fibres were found in the distal muscles of the legs. The conduction velocity of surviving fibres was reduced and the terminal latencies prolonged.

In a study of 84 patients with peripheral polyneuropathy Buchthal and Rosenfalck (1971) noted a group of 12 patients with a decrease of motor nerve conduction in whom a high distal latency was found. The authors gave no details of the pathological processes of these patients. Whether a special type of polyneuropathy is characterized by high terminal latency with reduced nerve conduction deserves further clarification.

List (1932) reviewed the literature up to 1932 on the pathology of peripheral nerves in acromegalic patients. He mentioned thickened, hard nerves with proliferation of connective tissue in the peri- and endoneurium accompanied by degeneration of nerve fibres. The spinal cord showed degeneration of the posterior columns. Lewis (1972) studied the sural nerve in one patient and found loss of large myelinated fibres and increased endoneurial collagen. No Schwann cell overgrowth and no 'onion bulb' formation were observed.

The peripheral nerves in the present case showed: (1) lamellar disintegration and vesicular transformation of the myelin, and (2) accumulation of endoneurial mucopolysaccharides and collagen. There was no 'onion bulb' formation.

Similar myelin changes have been reported in various unrelated conditions. Lampert (1967, 1969), Schröder and Krücke (1970) and Wiśniewski et al. (1969) demonstrated them in experimental allergic encephalomyelitis and neuritis. A similar pattern of demyelination was found in neuropathies due to diphtheria toxin (Wiśniewski and Raine, 1971), tellurium (Lampert et al., 1970; Lampert and Garrett, 1971), lead (Lampert and Schochet, 1968), $X$-irradiation (Masurovsky et al., 1967), and alcoholism (Babel et al., 1970). The common factor in the abovementioned demyelinating neuropathies was the initiation by injuries to Schwann cells. In the present case light microscopy did not show evidence of Schwann cell lesions and the electron micrographs were inadequate due to postmortem changes and formalin fixation. The abundance of the granular material between the myelin lamellae and around the nerve fibre indicates the Schwann cell location of this substance, presumably an acid mucopolysaccharide as shown with the histochemical study.

Excessive growth hormone causes an augmentation of intercellular ground substance and high concentration of acid mucopolysaccharides and collagen. Hypophysectomy reduces the synthesis of mucopolysaccharides and collagen in connective tissue (Catt, 1970). It seems likely that the growth hormone may have caused the accumulation of the mucopolysaccharides within the Schwann cells in the present case.

An excess of mucopolysaccharides within the endoneurium has been reported in various polyneuropathies. Thomas and Lascelles (1967) in a recent review on hypertrophic polyneuropathy found gelatinous material, probably acid mucopolysaccharide, in the endoneurial space. In an electron microscopic study of the nerves, however, no abnormal materiaf was found. The peripheral nerves in Refsum' disease showed imbibition of the nerves witlop an acid mucopolysaccharide without anf evidence of its presence in electron microscopic study (Fardeau et al., 1970; Flament-Duran\& et al., 1971). In hypertrophic polyneuropath (Thomas and Lascelles, 1967), and in Refsum's disease (Fardeau et al., 1970; Flament-Durand et al., 1971) 'onion bulb' formation is a striking feature which was absent in the present case.

The simultaneous appearance of hypertrophic polyneuropathy with lamellar disintegration, vesicular change in the myelin and accumulation of acid mucopolysaccharides without 'onion bulb' formation seems to be unique. It may be assumed that acromegalic polyneuropathy represents a pathological entity. Additional data from similar cases may clarify this assumption.

\section{REFERENCES}

Babel, J., Bischoff, A., and Spoendlin, H. (1970). Ultrastructure of the Peripheral Nervous System and Sense Organs, pp. 106-107. Thieme: Stuttgart.

Buchthal, F., and Rosenfalck, A. (1971). Sensory potentials in polyneuropathy. Brain, 94, 241-262.

Catt, K. J. (1970). Growth hormone. Lancet, 1, 933-939.

Fardeau, M., Abelanet, R., Laudat, P., and Bonduelle, M. N (1970). Maladie de Refsum. Etude histologique, ultrastructurale et biochimique d'une biopsie de nerf périphérique. Revue Neurologique, 122, 185-196.

Flament-Durand, J., Noël, P., Rutsaert, J., Toussaint, D., 
Malmendier, C., and Lyon, G. (1971). A case of Refsum's disease: clinical, pathological, ultrastructural and biochemical study. Pathologia Europaea, 6, 172-191.

Lampert, P. (1967). Electron microscopic studies on ordinary and hyperacute experimental allergic encephalomyelitis. Acta Neuropathologica, 9, 99-126.

Lampert, P. (1969). Mechanism of demyelination in experimental allergic neuritis. Electron microscopic studies. Laboratory Investigation, 20, 127-138.

Lampert, P. W., and Schochet, S. S., Jr. (1968). Demyelination and remyelination in lead neuropathy. Journal of Neuropathology and Experimental Neurology, 27, 527-545.

Lampert, P., Garro, F., and Pentschew, A. (1970). Tellurium neuropathy. Acta Neuropathologica, 15, 308-317.

Lampert, P., and Garrett, R. S. (1971). Mechanism of demyelination in tellurium neuropathy. Electron microscopic observations. Laboratory Investigation, 25, 380-388.

Lewis, P. D. (1972). Neuromuscular involvement in pituitary gigantism. British Medical Journal, 2, 499-500.

List, C. F. (1932). Doopelseitige Medianusneuritis bei Akromegalie. Zeitschrift für Nervenheilk, 124, 279-292.

Lucey, C. (1972). Neuromuscular involvement in pituitary gigantism. British Medical Journal, 3, 49-50.
Masurovsky, E. B., Bunge, M. B., and Bunge, R. P. (1967). Cytological studies of organotypic cultures of rat dorsal root ganglia following X-irradiation in vitro. 2. Changes in Schwann cells, myelin sheaths, and nerve fibers. Journal of Cell Biology, 32, 497-518.

Oppenheim, H. (1923). Lehrbuch der Nervenkrankheiten fiir Arzte und Studierende. Vol. 2, 7th edn. Karger: Berlin.

Sainton, P., and State, J. (1900). La forme douloureuse de l'acromégalie. Revue Neurologique, 8, 302-310.

Schröder, J. M., and Krücke, W. (1970). Zur Feinstruktur der experimentell-allergischen Neuritis beim Kaninchen. Acta Neuropathologica, 14, 261-283.

Thomas, P. K., and Lascelles, R. G. (1967). Hypertrophic neuropathy. Quarterly Journal of Medicine, 36, 223-238.

Wiśniewski, H., Prineas, J., and Raine, C. S. (1969). An ultrastructural study of experimental demyelination and remyelination. 1. Acute experimental allergic encephalomyelitis in the peripheral nervous system. Laboratory Investigation, 21, 105-118.

Wiśniewski, H., and Raine, C. S. (1971). An ultrastructural study of experimental demyelination and remyelination. 5. Central and peripheral nervous system lesions caused by diphtheria toxin. Laboratory Investigation, 25, 73-80. 